\title{
Out-group Peer Involvement in Youth Alcohol Consumption
}

\author{
H.P. Samanthika Gallage* (Corresponding author) \\ Nottingham University Business School, UK \\ Jubilee Campus, Wollaton Road, \\ Nottingham, NG8 1BB, UK \\ Hakmana.Gallage@nottingham.ac.uk \\ T: 01157484677. \\ Caroline Tynan \\ Nottingham University Business School, UK \\ Jubilee Campus, Wollaton Road, \\ Nottingham, NG8 1BB, UK \\ caroline.tynan@nottingham.ac.uk \\ T: 1158466978. \\ Teresa Heath \\ Nottingham University Business School, UK \\ Nottingham University Business School, UK \\ Jubilee Campus, Wollaton Road, \\ Nottingham, NG8 1BB, UK \\ Teresa.pereiraheath@nottingham.ac.uk \\ T: 1159515268.
}




\section{Biographies}

Samanthika Gallage is an academic at the University of Sri Jayewardenepura, Sri Lanka and is currently conducting her doctoral research at the Nottingham University Business School. Her doctoral study is related to social marketing in the context of youth alcohol consumption. She is interested in studying these social issues using identity theories and emotions specifically contributing to the domain of social marketing and consumer behaviour.

Caroline Tynan is Professor of Marketing at Nottingham University Business School, University of Nottingham in the UK, President of the Academy of Marketing, a Visiting Professor at The University of Ljubljana in Slovenia, and a Fellow of both the Academy of Marketing and the Chartered Institute of Marketing. Her research interests focus on value cocreation, consumption meanings, experience marketing and luxury goods marketing. She has published in the Journal of Business Research, the European Journal of Marketing and the Journal of Marketing Management.

Teresa Heath is Assistant Professor of Marketing at the Nottingham University Business School. Her publications and research interest focus primarily on consumption, sustainability, and critical marketing. She has published in a number of journals, including the Journal of Business Ethics, the European Journal of Marketing, International Journal of Consumer Studies and the Journal of Marketing Management. She received her doctoral degree from the Nottingham University Business School. 


\title{
Out-group Peer Involvement in Youth Alcohol Consumption
}

\begin{abstract}
Recent studies of alcohol consumption among students have consistently linked in-group influence with excessive drinking. Concurrently, these studies have largely overlooked the influence of non-alcohol-consuming peers (the out-group) on the in-group's decisions to consume alcohol. However, out-groups can have a significant impact on in-group members' decisions regarding publicly consumed products (White et al. 2014), such as is the case of alcohol. In light of this, our study aims to explore how in-group members' views of their consumption of alcohol are influenced by their out-group. This study uses Social Identity Theory as the theoretical lens to explain consumer interaction with the out-group (abstainers) and subsequent views of in-group members (alcohol consumers). A social-constructivist approach is adopted to enable this exploration of meaning, with concomitant use of the qualitative narrative methodology. A sample of 18 post-graduate students studying in the UK was selected. Narratives were collected and analysed using thematic analysis. While the widely accepted view is that people tend to avoid products or behaviours that are linked with an outgroup, this paper demonstrates conditions in which alcohol consumers appreciate the out-group. Furthermore, it reveals how drinkers' interaction with their out-group can lead to negative attitudes towards their in-group and their own consumption of alcohol. Based on their views of out-groups, we propose a categorisation of alcohol consumers into three groups: avoiders, open admirers and covert admirers. Finally, we discuss the theoretical and practical implications for social marketers and policy makers.
\end{abstract}

Key words: out-group, social identity theory, alcohol consumption, social marketing 


\section{Out-group Peer Involvement in Youth Alcohol Consumption}

\section{Introduction}

Excessive alcohol consumption is an issue of concern within student populations, especially within the UK (Piacentini and Banister, 2009). A survey of UK university students revealed that only $11 \%$ report being non-drinkers, whereas all other students consume alcohol, of whom nearly $40 \%$ are binge drinkers (Webb et al. 1998). This problem has been aggravated by new media platforms that increasingly expose the young to pro-alcohol messages (see Moraes et al. 2014). More recently, a survey by The Varsity (the of the University of Cambridge's daily newspaper) showed that excessive drinking is part of UK student culture, which has created much social and medical harm (The Varsity, 2015). Its consequences include: missed classes and decreased academic performance (Ham and Hope, 2003); fighting and property damage (Rinker and Neighbors, 2014); increased risk of sexual violence and the medical consequences of unprotected sex (Anderson et al. 2009); and, at the extreme end of the spectrum, increased morbidity and mortality (Sher and Rutledge, 2007).

While in-group peer pressure is a well-established phenomenon and considered a major influence on alcohol consumption (see e.g. Heath, 2000; Piacentini and Banister, 2009; Borsari and Carey, 2001), the influence of out-groups has been overlooked. The paucity of work done on out-groups and the need to explore out-groups' influence on consumer decisions have been noted in consumer studies (e.g. Escalas and Bettman, 2005; Choi and Winterich, 2013). The present article redresses this neglect and explores how interactions between an in-group (alcohol consumers) and an out-group (abstainers) affects in-group members' views of alcohol consumption and thereby their predisposition to change their behaviour. This study adopts the theoretical lens of Social Identity Theory (SIT), which posits that people define their selfconcepts by their connections with social groups or organisations (Tajfel and Turner, 1979). SIT explains that people differentiate themselves from others, distinguishing between in-groups and out-groups (Hogg and Abrams, 2001; Brown, 2000; Stets and Burke, 2000).

This study draws on 18 interviews conducted in the UK with Indian postgraduate students. Indian students leave their families to come and study in the UK, and have to adapt to a new culture, educational system and environment. This life transition, when students begin to assimilate into a new status and adapt to new roles and identities, is a period of disequilibrium (see McAlexander, 1991), which makes students particularly vulnerable to excessive alcohol consumption. This is particularly important when excessive drinking has been increasing among South Asian students in the UK (Heim et al. 2004), with Indians being especially likely to drink regularly or beyond recommended levels (Cochrane and Bal, 1990).

This article begins with a brief review of the extant literature on youth alcohol consumption, peer group involvement with alcohol consumption and SIT. Subsequently, it presents the methodology employed which consists of 18 narrative interviews with Indian postgraduates in 
the UK. It then reports and discusses the findings obtained, before drawing conclusions and discussing implications.

\section{Theoretical Background}

Alcohol consumption has been the focus of many studies in social marketing (e.g. Cherrier and Gurrieri, 2013; Fry, 2010; Piacentini and Banister, 2009), where the terms binge drinking and excessive drinking are frequently used interchangeably (Szmigin et al. 2011; Borsari and Carey, 2001). Szmigin et al. (2011) distinguishes excessive drinking, used to describe a single drinking session leading to intoxication, from binge drinking, which refers to "pattern of heavy drinking that occurs over an extended period of time set aside for the purpose" (Herring et al. 2008, p. 476). Both terms refer to drinking behaviour that is excessive and thus represent a matter of current social, media and political concern in the UK (Hackley et al. 2013; Alcohol misuse manifesto, 2015).

Many social marketing initiatives have been introduced to tackle the problem of alcohol consumption. The UK government's 2010 and 2011 public health white papers discuss the "power of social marketing" and the usefulness of marketing tools to change behaviour and promote well-being (Public Health White Papers, 2010, 2011). Despite this, the youth alcohol problem persists in the UK (Piacentini and Banister, 2006; Szmigin et al. 2011).

Factors affecting excessive drinking include peer and family influences (Ham and Hope, 2003), wider social norms (Wechsler and Kuo, 2000), marketing efforts such as advertising (Griffin et al. 2009) and cultural shifts (Measham and Brain, 2005). Many health studies dealing with alcohol consumption focus on specific ways in which in-group peers can influence each other's alcohol consumption, using the theoretical lens of Social Learning Theory (SLT) (see Reed et al. 2007; Bot et al. 2005; Mooney and Corcoran, 1991). SLT explains how people learn from others through observation, imitation and modelling of the behaviour of their peers (Borsari and Carey, 2001). While these studies have illuminated how young people are influenced by their in-group peers, they do not specifically explain why this should occur and overlook the influence of out-groups. In this study, we address this neglect. We draw on SIT as this theory explains the process by which individuals define themselves with regard to both their in-groups and out-groups.

According to SIT, individuals define their self-concept by their connections with social groups or organizations (Tajfel and Turner, 1986). They tend to categorise themselves based on their perception of differences and similarities between themselves and particular groups; the ingroup being the group they consider themselves similar to, and the out-group being the group they consider themselves different from (Hogg and Abrams, 2001). As a consequence, they respond more positively to their in-group (Escalas and Bettman, 2005; Choi and Winterich, 2013). In our study, participants self-defined their in- and out-groups on the basis of alcohol consumption with the in-group being those who consume alcohol and the out-group being those who abstain. This follows White et al.'s (2014) study where participants categorised themselves 
based on their academic discipline, with business students being deemed the in-group and computer science students the out-group.

Many consumer studies into group membership have focused on the role of in-group influence in determining an individual's attitudes and behaviour (Bearden and Etzel, 1982; Park and Lessig, 1977). However, the influence of out-groups on consumer identity and decision making has been largely unexplored (White and Dahl, 2006, 2007). The few studies which have focused on out-groups suggested that consumers reject, avoid or negatively assess products, brands or behaviours that are associated with the out-group (Escalas and Bettman, 2005; White and Dahl, 2006, 2007). This is particularly the case in the context of publicly consumed, symbolic products (White and Dahl, 2006) and when the in-group identity is important to consumers (White and Dahl, 2007), as with alcohol consumption. In contrast, using an experimental methodology, White et al. (2014) found that communicating positively viewed actions of outgroups can lead in-group members to be more inclined to copy out-group behaviour, which demonstrates a novel and paradoxical effect of out-groups. This is demonstrated in the successful social-marketing campaign "Walking to school", which portrayed positively children who walk to school (the out-group) as happy, fit and ready to learn rather than disparaging the in-group who do not walk to school (Living Streets, 2017). Our present study explores this issue further by illuminating how out-groups can be used to positively change the behaviour of in-group members.

\section{Methodology}

Many previous studies of youth alcohol consumption have adopted a positivist approach and established a positive causal relationship between in-group peer influence and alcohol consumption (see e.g. Reed et al. 2007; Bot et al. 2005). This study adopts an interpretivist approach, aiming to develop a more contextual understanding of how the interaction between in-group and out-group affects the subsequent views of alcohol consumption of in-group members. Taking the view that reality is socially constructed, we explore how in-groups collectively create meanings and shape the behaviour of their members during social interactions (see Hudson and Ozanne, 1988). Thus, a concern for the "lived experiences" of our participants and for how these were felt and understood by them (see Schwandt, 1994, pp. 118), guided our data collection and analysis.

We use a narrative approach, which is especially suited to explore culturally-embedded, and context-specific consumption acts (Shankar et al. 2001), such as is the case of drinking. The narrative method has a rich history and is widely used in variety of disciplines such as sociology, psychology, economics, political sciences, history (Bold, 2011) and more recently marketing (Pace, 2008; Shankar et al. 2001). By encouraging participants to recount and revisit their "drinking stories", we allowed them to create a world and represent themselves in that world (Schiffrin, 1996) with vivid details. Specifically, narratives enabled us to capture the contexts and nuances of participants' interactions with their in-group and out-group and the meanings created in these interactions (see Szmigin et al. 2008; Hackley et al. 2013; Griffin et 
al. 2009). This helped us to uncover the fluid and contextual nature of the identities that participants construct (Ricoeur, 2002) especially during life transitions (Barrios et al. 2012).

To collect the data, we used an in-depth interviewing method as it is considered one of the most effective ways to obtain individuals' narratives (McCracken, 1986; Riessman, 2008). Thus, data collection was conducted through 18 long, in-depth, face-to-face, narrative interviews. To ensure that participants recalled their experiences in full, we used probing and gave especial attention to context and detail (Alvesson, 2003). We used a snowballing method to identify Indian postgraduate students of both genders, aged between 21 and 26 years, who are: enrolled at one of two universities in the English Midlands; come from a variety of backgrounds and have a wide variety of religious beliefs including Hinduism, Sikhism, Jainism, Islam, Orthodox Christianity and Catholicism; and self-reported drinking excessive amounts of alcohol. These details are summarized in Table 1 in the appendix, which shows age, gender, upbringing, and religious background for each participant. As we will explain, these last two aspects revealed to be important to understand participants' narratives. The interview guide was structured loosely (Piacentini and Banister, 2006) so as to let participants freely narrate their stories. In interviews lasting for between 45 and 70 minutes, participants were asked about their circle of friends in the UK, alcohol consumption habits, and stories of coming to the UK and forming friendship groups. These interviews were conducted in English and were transcribed verbatim from audiotapes, with pseudonyms used to preserve the anonymity of participants (See Fry, 2010).

Narratives were analysed using thematic analysis (Riessman, 2008). Firstly, the lead researcher read the entire set of transcripts independently to become familiar with the data (Riessman, 2008) and the overall shape, meanings, context of experiences (Creswell, 2009). This task was made easier as she conducted all the interviews herself and kept contemporaneous notes of observations. Then this researcher sought key phrases, metaphors, repetitive patterns of similar meanings and differences (Ryan and Bernard, 2003; Braun and Clarke, 2006) by manually coding them. Initial codes were guided by SIT, reference group and alcohol consumption literature, while some others emerged from the data itself (Miles and Huberman, 1994). After the initial coding and after all three researchers become familiar with the data, themes were derived independently by the each of them and negotiated until a consensus was reached (see Price et al. 2000).

\section{Findings}

In this section, we present analysis and discussion concurrently. Our findings suggest that participants have different experiences and perceptions of their alcohol consumption behaviour based on their level of interaction with the out-group and unexpectedly their own family background, which emerged from participants' own accounts. In the following we will examine these differences by analysing participants' self-definition of their group memberships, their family background and how different groups of drinkers relate to their out-group. 


\section{Participants' Self-definition of their In- and Out-groups}

Firstly, participants spontaneously associated their in-groups with individuals who consume alcohol, to whom they felt similar (Hogg and Abrams, 2001), and the out-group with those who do not consume alcohol from whom they felt different. Kumar illustrates this:

My closest friends group is my flatmates. Every Friday we drink and go clubbing. They call me whenever they drink and it's not about drinking and having fun only, but we sometimes talk about more mature stuff as well. It's all about bonding you know. ... Most of my other friends who don't drink I do not meet quite so often. We just catch up through the phone. But there is no bonding. There is no 'relax time'. I don't get a time to hang around with them. (Out-group). $\{$ Emphasis added $\}$ (Kumar, male, 25 years old)

His narrative clearly reveals that he constructs an in-group (called "we"), consisting of consumers of alcohol and an out-group ("them") of non-drinkers. He claims membership of the group who drink and dissociates himself from the "other" group who do not drink. Kumar also tries to show his in-group in a more positive light by highlighting the mature conversation, bonding, relaxation and fun they experience (see also Piacentini et al. 2012). Similarly, Kanna explains:

While we are drunk and when there is a sober person it is not upon the person who drinks. But the challenge is with the sober person how to interact with us. So these non-drinking people just try to get along you know. They just try to talk and tolerate all the nonsense happening around you ......But sometimes they don't come to hang around with us. They have their own ways of enjoying and relaxing. But there are not many people like that. So it must be hard for them to find people to enjoy the life with. \{Emphasis added\} (Kanna, male, 26 years old)

Kanna clearly distances himself from "these non-drinking people" ("they" versus "we") and places responsibility on them for dealing with the outcome of the drinking behaviour of the ingroup. Thus, he sees this as a "challenge" for them, which "must" make it "hard for them to find people to enjoy" life with. He also continuously associates alcohol with enjoyment and pleasure and points out how hard it is to be an abstainer in the dominant consumption culture ("there are not many people like that"). This rejection of the out-group corroborates the findings of consumer behaviour studies using Social Identity Theory (e.g. Hogg and Abrams, 2001; Escalas and Bettman, 2005).

\section{Participants' Family Background and Alcohol Consumption}

When discussing attitudes to alcohol consumption participants raised issues related to their family background and, in particular, religious beliefs. Participants came from a diverse range of family backgrounds and religious beliefs; specifically, some participants came from families who were very strict concerning the decisions of their children, whereas others were far more laissez faire (see Table 1). Juhi, explained her family background as follows: 
I am a Sikh. So my family is like a conservative, proper Punjabi Sikh family. My family is really strict regarding this (alcohol) [...] There is something written in the holy book like cigarettes, alcohol is like really bad, if you actually do it you go to hell. It's a sin for us. So my Dad is very strict on this [...] In India we don't drink because obviously we have to go back to our family home. [...] I don't think any girl of my family background gets drunk and goes home because she would be kicked out of her house. \{Emphasis added\} (Juhi, female, 22 years old)

Juhi's narrative illustrates that her family in India is very religious with a high level of control exercised by the senior members of the family over the young. Other respondents from similar strict backgrounds expressed the same view. This is similar to Rizwan in that his parents exercise control over many of his buying decisions, as he explains:

My family is an Islamic family and they are strict as any Muslims. We do all kind of rituals that Muslim do and believe in everything like halal, no pork, no drinks and fasting.... My Dad was here in the UK a couple of months back, he was quite concerned about what I am buying... where is it from? Is it Halal? Is it alcohol? \{Emphasis added\} (Rizwan, male, 25 years old)

However, other participants reported having the freedom to make their own decisions. For example, Shahruck comes from a rich upper class family who do not hold to strict religious beliefs, leaving him free to make his own decisions including those about alcohol:

My parents introduced me to alcohol after I turned 18. So, I never had to sneak out of the house to get drunk with friends and not tell parents. So that was never a question for me... My family is not a very religious family. We follow all the religious activities because of my grandparents. (Shahruck, male, 22 years old)

As we see from these examples, participants' views on, and meanings attributed to alcohol are shaped within the cultural and religious contexts of their families and influence their alcohol decisions.

\section{Types of Alcohol Consumers}

Findings suggest that participants can be categorised according to how they respond to their abstaining out-group. Data suggested three different consumer groups; avoiders, open admirers and covert admirers. The members of each of these three categories tend to exhibit similar characteristics with regard to their family background and hold different views of their outgroup which seem to affect their views of alcohol consumption. The level of involvement with the alcohol abstaining group, i.e. the out-group, is the degree to which consumers interact with their out-group colleagues.

Avoiders

Members of the avoiders group have less interaction with the out-group than members of the other groups have; they believe the out-group to be unfashionable and boring, and therefore 
avoid them completely. Most of these respondents come from families that exercised a high level of control over their adult children. Sonakshi says:

My parents are religious where they engage with their day to day Poojas and stuff... Yes it is that, when you have freedom, you should try out as many things as possible other than drugs. You have a short life to be regretted and stick inside rules... Me and my closest friends (ingroup) think things in common because we all believe in having these balanced lifestyles. Also, all of us think that we should have fun despite of studies. Basically, my group does both. So I like to be with this group... I don't have any close friends who do not drink in the UK. Alcohol helps me to relax and I feel happy. \{Emphasis added (Sonakshi, female, 25 years old)

Sonakshi seems to attribute her current willingness to "try as many things as possible" to her strict upbringing. Sonakshi, like other avoiders, sees the out-group as a dissociative group by contrasting the full and fun life of their in-group with the unexciting and restricted way of life of non-drinkers. This finding supports previous studies which found alcohol consumption to be central to the development of social experience in students' lives and their resulting social identities (Measham and Brain, 2005; Piacentini et al. 2012) and identities as students (Piacentini et al. 2012).

Ranjan went further to explain that he trusts the alcohol drinkers more than non-drinkers:

Alcohol helps me loosen up and sort of relax. When I have a drink, I forget about all and make friends so it's like that ... So I can say that the people I drink with are closer to me because when we have a drink we tend to share lot of our problems and all. So we have someone to talk to. I think people bond 'more well' (sic).... I can trust someone who drinks more than someone who doesn't. Drinkers can understand you well. The friends that drink with me (thinking) thing is that I trust them more. Because they are the people who have always been with me whenever I had a problem. I can tell them "mate I am going to break up" or something like that like they are always there for me no matter what. And the thing is I tend to click with them there is more of a brotherhood or something like that than the friends whom I don't drink with. .... When you have a drink or something you tend to trust someone more and they tell you stuff you tell them stuff. So there is a companionship. Also, people who drink they don't lie. So that is one factor. I guess because you know them and whatever he is saying he is telling the truth. So you tend to trust that person... \{Emphasis added (Ranjan, male, 22 years old)

Ranjan's narrative is redolent with positive, rich and expressive language, such "brotherhood", "companionship", "understanding", "trust" and "bond". Ranjan views his in-group as being like a close, supportive family, who "don't lie" to each other. This is consistent with other studies that find alcohol is a "glue" that binds groups together (Griffin et al. 2009). At the same time Ranjan is implicitly contrasting this trusting and superior in-group with the others who do not drink.

These findings support the SIT notion of in-group favouritism by showing that group members see their own group and their acts as superior to those of other groups (Brown, 2000; Terry et 
al. 1999). Thus, a relatively positive social identity is created in comparison to the out-group. Participants construct the in-group as "superior", "more balanced", "more trustworthy", "funnier" or "cooler" to be with. They do not view alcohol as a problem and try to dissociate themselves from those who believe it is. To the extent that Sonakshi and Ranjan distance themselves from less trustworthy and less companionable abstainers, these results are also consistent with Piacentini and Banister (2009) who found that drinkers try to exclude and socially stigmatise non-drinkers.

\section{Open Admirers}

The second group of alcohol consumers report high levels of interaction with the out-group. When we looked at these participants' backgrounds, we noted that most of them came from families where they enjoyed freedom in their decision making before coming to the UK. This group openly admire the out-group and challenge the widely accepted view of non-drinkers as "unfashionable" (Cherrier and Gurrieri, 2013). Maduri says:

My parents are very social and they consume alcohol [...] I quickly got hold of a group who went out to socialise and feel free. Obviously, they were drinkers. It's because there is a part of me that believes that people who consume alcohol are freer and also they don't hold themselves back. I enjoy having a drink so it became a plus point for me to be in an exciting, outgoing group... The transition from not knowing any and getting to know somebody, of first meeting to becoming friends and I think alcohol just smooths the process [...] I sometimes get repulsed by people who only talk about alcohol all the time. When we gonna drink next? When we go out next? [...] So that's something I appreciate about the non-alcoholic consumers, that I can sit down and have a genuine conversation with them because I think the time they don't waste go out and drinking alcohol they use more wisely. So I feel like I have so much to learn... I can have any type of a conversation with a non-drinker. There are some days that I don't feel like drinking. So I want someone sober to talk with me. At that point I feel non-drinkers are ideal... They must be putting the time that we waste on binge drinking for something worthwhile. I think I should learn from them. \{Emphasis added\} (Maduri, female, 23 years old)

Maduri builds a narrative that starts by idealizing alcohol as something that facilitates socialization within an "exciting", outgoing group", which seems to be particularly important at this "transition" stage. Interestingly, Maduri later describes alcohol consumers as sometimes being "repulsive" and overly focused on drinking and partying. Thus, while she first associates a positive meaning with this consumption, she later rejects that identity and praises the outgroup for their sobriety and for using their time for "something worthwhile". Indeed, some days she feels like having a conversation with a sober person, who then becomes "ideal". Similarly, other respondents portray abstainers as being "better off" than drinkers and they openly admit this to abstainers. For instance, Sasen explains:

I think they (out-group) are better off. Like you know I think they are twice as better off as I am. I would prefer to be bit away from it (drinking) because of the health reasons. I would be proud 
to say that. I even tell this to them too [...] Like I said alcohol is not good, that's not good for your health and I am really figure conscious as you can see so I am really conscious about what happens to me. \{Emphasis added\} (Sasen, male, 22 years old)

Overall, our participants' narratives indicate that students who consume alcohol are aware of the negative consequences and downsides of their consumption decision, which is consistent with previous studies (e.g. Piacentini et al. 2012). However, Open Admirers go beyond this to openly highlighting the superiority of abstainers over them in aspects including their productive use of time, ability to discuss cogently and health consciousness. This contradicts SIT where the out-group is always rejected and considered inferior to the in-group (Tajfel and Turner, 1986). We propose that the contradictory views inherent in this group relate to different identity activations in different situations. Social identity theorists originally used the term salience to indicate this activation of an identity in a particular situation (Stets and Burke, 2000); different activated identities generate different feelings and behaviours (Stets and Burke, 2000). Maduri's account illustrates how different identities can be activated in different contexts; her "drinker identity" emphasizes the social and partying elements of this world while later her "serious student identity" wants to learn and have intelligent conversations. Hence, participants' reactions are situational and context specific; in some situations, this group feels that their ingroup is superior, act according to their group norms and enjoy alcohol consumption, while in others they prefer the out-group and feel uncomfortable with their consumption decision.

\section{Covert Admirers}

The third group comprises alcohol consumers who have a high level of interaction with their alcohol abstaining out-group and admire them secretly. Most respondents in this came from strict families which exercised a high level of control over their decisions. As alcohol symbolises fun, friendship and togetherness (Szmigin et al. 2008) many respondents in this study revealed that alcohol is a key determinant in their decision to join an exciting in-group. Despite this, they secretly admire the non-drinkers whom they consider wise and "better than me". Simultaneously, they feel guilty and even ashamed of their behaviour, especially when they think of their families, as Juhi explains below.

I have friends who don't drink at all...I like them (abstainers). They both enjoy and control themselves [...] Truly there were days I feel that they (abstainers) are much better than me. But I never say it to them directly... But when I remember my Dad's face sometimes I feel guilty [...] Even with such freedom they don't drink. Another good thing that I noticed the people who don't drink at all is that they don't preach to you against drinking, if you know what I mean. (Juhi) \{Emphasis added $\}$ (Juhi, female, 22 years old)

Wadiya attempts to justify her behaviour in terms of taking advantage of the sudden freedom available away from her conservative parents:

I was not feeling right at the time because I felt like that I am doing something bad and it is not just bad for me but also for my family. Since I was raised in a very conservative family I 
have never experienced this and because I am a girl I don't think my parents would expect me to behave the way I do now. So I really think they would not be happy with my behaviour and what I fear the most is that they would lose trust over me and would never trust me on anything and also they would see me as an irresponsible person [...] Sometimes I feel tired of alcohol. My friends ask me to take one or two shots due to various reasons. Farewell party for someone, or a celebration or in sharing a sorrow. There is always a reason for them to get drunk [...] It is their (non-drinker's) choice not to drink in the first place so I think they made their decision wisely [...] I think what happened to me has happened to most Indian students. They have all came here and seen the freedom available for them and used it. But I think all Indian students are conservative deep down and they have the guilt of lying to their parents; especially girls. (Wadiya, female, 22 years old)

Interestingly, Wadiya has come to realize that she feels "tired of alcohol" and has lost the reason for her initial engagement with it. These conflicting views represent an example of what Brown (2000) named "unsatisfactory identities" (p. 747), which may arise as people seek to leave their existing groups. Indeed, in parts of her account, Wadiya attempts to dissociate herself from her in-group of drinkers (e.g. "There is always a reason for them to get drunk"). Jeshan, below, expresses a similar disenchantment and recognizes that the out-group can actually have more fun than his in-group. This is again in contrast with one of the main assumptions of SIT which suggests that the in-group is always considered superior to the out-group (Tajfel and Turner, 1986). Here, unlike the portrait of the out-group as uninteresting, boring and disengaged, Jeshan admires and likes non-drinkers as people who can maintain their health, "sing", "dance", "entertain" and even "take care" of those who drink to excess.

I think non-drinkers are amazing because they know how to adapt themselves to any environment. They have more self-control than us. .. I wish to join with that group secretly. They have different hobbies and different ways of enjoying. I have a friend who does not drink alcohol. But the fellow knows how to sing, dance and even to entertain us. He also can take care of us when we are too drunk. I think he is amazing... So I don't think I will be able to fit into this group. The thing that I like about them is enjoying even most simple things like a song, nature or anything. Also it does not harm your health too. .. I was in this habit for so long and now I want to get out it. But I believe now I can't get into a new group of friends and find new things to enjoy. Time is very limited when you do a masters. So I will stick with it until I finish this. \{Emphasis added (Jeshan, male, 23 years old)

It is also important to note that both Jeshan and Wadiya talk of a "secret" desire to change their behaviour. This is a useful inversion and extension for the argument of Berger and Rand (2008) who found that associating risky health behaviour with an out-group could contaminate that unhealthy behaviour for the in-group, making them less likely to engage in it. However, in the present study associating the healthy and overall positive behaviour with the out-group contaminates the drinking behaviour of the in-group, leading them to question their risky choices and thus making them more likely to change them. However, as Jeshan indicates, making such a decision is challenging, which may justify the "secrecy" of his admiration. 
These three groups (Avoiders, Open Admirers and Covert Admirers) show different views of their out-groups. These views ultimately shape in-group's members views of themselves and of alcohol consumption. As these findings suggest, knowledge of out-groups' positive behaviour can be instrumental in encouraging positive behavioural change from the in-group members, which corroborates White et al. (2014) in that publicly-viewed positive actions of dissociative out-groups can encourage in-group members to change their behaviour. However, some participants, such as "avoiders" intentionally eschew the non-drinking out-group behaviour in order to justify their perceived superiority over that group (see also Brown, 2000). Members of this group place a high level of emotional significance on their in-group and try to create an identity by adopting their in-group prototype, which is congruent with the SIT arguments of Tajfel and Turner (1986). Open admirers and covert admirers have a higher involvement with the non-drinking out-groups and realise the benefits of their behaviours. Hence, open admirers accept the superiority of the out-group in some regard due to different identity activations (see Stets and Burke, 2000) while covert admirers experience ambivalent emotions and secretly question their group membership or wish to change it. Hence, both the open and covert admirers could be persuaded to engage in behavioural change. Importantly, as suggested by previous studies (White el al. 2014) out-groups and their choices are not necessarily being shunned by in-group members. Contrary to this, in some situations, gaining awareness of the positively viewed behaviours and identities of the out-group may encourage in-group members towards changing their behaviour.

\section{Conclusion and Implications}

This study challenges current understandings of SIT, which suggests that responses to the outgroup would be necessarily negative or dismissive (see White and Dhal, 2006, 2007; Berger and Rand, 2008). Specifically, we found that in some situations the perceived positive actions of non-drinking out-groups can positively "contaminate" in-group behaviour. This effect is not straightforward and we identified three different categories of in-groups of alcohol consumers: avoiders, open admirers and covert admirers. These groups respond differently to the abstaining out-group and their alcohol consumption. Which group a participant falls within seems related to family background with the level of control exercised by participants' families over their decisions varying little within groups. Both avoiders and covert admirers tend to come from strict families whereas open admirers disproportionately come from more tolerant family backgrounds. Avoiders construct a view of their in-group as "superior" and they explicitly avoid the out-group. Both open and covert admirers interact freely with the outgroups, have negative feelings about their own personal alcohol consumption, realize the benefits of abstention and struggle between identities as fun-loving drinkers and wise nondrinkers. However, while open admirers seem content with their in-group membership and openly praise the out-group, covert admirers try to dissociate themselves from the in-group membership while secretly aspiring to be more like the out-group. Indeed, their narratives suggest that they would potentially leave their in-group if they were given support. 
These findings have important theoretical and practical implications. Firstly, this study highlights the importance of considering the ways in which participants, together with their immediate in-groups or in interactions with out-groups, construct understandings of themselves and of the out-groups. Attention to participants' stories, contradictions and emotions allowed us to identify contexts in which out-groups can exert a positive influence on in-groups, which defies current understanding of SIT and expands knowledge in social marketing. Secondly, this study adds insights into the reference-group literature, which has overlooked the role of dissociative reference groups in consumer behaviour (Escalas and Bettman, 2005; White and Dahl, 2006, 2007). While most studies on reference-groups have focused on the impact of ingroups, the current study suggests that positive actions by out-groups can lead other consumers to engage in similar positive behaviour. This also emphasises the need for a deeper understanding of the nature and role of out-groups, and of their positive, as well as negative, influence on in-groups. Finally, the suggested influence of family background on the attitudes and behaviour of our participants highlights the importance of taking a wider contextual and relational view of alcohol consumers rather than looking at them simply as independent individuals, which agrees with previous findings on complex consumption decisions (e.g. Heath et al. 2016).

This understanding has important practical implications for social marketers, policy makers, universities, families and students with regard to alcohol consumption. Firstly, it is important that all parties acknowledge the importance of social groups in influencing alcohol consumption both positively and negatively, rather than focusing only on the role of individual personal responsibility. Therefore, alcohol interventions should consider the powerful effect of in-group membership rather than treating drinking as an independent decision. In a more practical way, social marketers can utilize the knowledge of different categories of in-groups to target each with specific alcohol reduction strategies that take their specific contexts in consideration. For example, communication strategies can highlight the positive behaviour of the out-group reflected in their lifestyles and hobbies, while reinforcing the cognitive dissonance and guilt of open and covert admirers. However, although guilt-related communication methods are considered an effective method of changing consumer behaviour (Antonetti et al. 2015), for our participants these were on-going emotions that alone did not seem to provoke any positive change. Thus, other social marketing interventions could be conceived. For example, campaigns could also be targeted to those that may wish to change their behaviour (covert admirers) but do not feel able to do so by showing that such a change is feasible and by facilitating this change. Also, as avoiders want to isolate themselves from the out-groups, strategies could be used to encourage more interaction with the out-group, which would allow alcohol consumers to appreciate the positive aspects of their out-groups behaviour.

Further, given that identity-based interventions can be useful in improving consumer health (Berger and Rand, 2008) and drawing on our results, social marketers can use communication methods to shift positive identities (cool, exciting, fun) associated with alcohol consumers into negative ones (unwise, impetuous, spendthrift) and inversely shift the negative identities associated with out-groups (boring, unexciting) into positive ones (fun, in control, wise, caring). 
Public policy makers and charities tend to focus on upstream social marketing interventions to promote alcohol abstinence or responsible drinking (Hoek and Jones, 2011). However, any attempt to understand the behaviour of a social group needs to be grounded in the dominant culture in which it operates (Piacentini and Banister, 2006). In our case, participants come from a variety of cultural and family backgrounds within India, which clearly affects their views of, and attitudes towards, alcohol consumption. In particular avoiders seem to try to experience the dominant culture of intoxication within the short time they live in England. Therefore, when implementing these interventions these differences should be taken into account. Further, these findings may be of use to other organisations who are aiming to encourage consumers to engage in positive actions (e.g. sustainable consumption, smoking cessation, recycling) by illuminating the positive aspects of out-groups' membership.

Finally, our findings suggest that the strictness of one's upbringing can affect attitudes towards alcohol when being temporarily placed in a different culture. Specifically it seems that students who come from strict family backgrounds seek out as many new experiences as possible during their stay away from their cultural heritage, including drinking and clubbing. Although further studies are needed to explore this more fully, this information can be useful for both university administrators and parents.

While this study limited its sample to university students in the Midlands of the UK, further research into a broader population within the UK would be an interesting extension of evidence. Researchers could also usefully explore the out-group involvement among other ethnic groups and a comparison would provide a broader understanding of both alcohol consumption and outgroup involvement in decision making. Researchers could further look into the views and perception of the out-group of alcohol abstainers about alcohol consumers and how they see the problem associated with alcohol. Another potential direction for further research is to examine the effects and the role of out-groups on in-group with regard to other consumption contexts. This will help to understand whether this counterintuitive argument about out-groups is only valid for socially unacceptable behaviours or not. 


\section{References}

All party parliamentary alcohol misuse manifesto. 2015. Available at http://www.alcoholconcern.org.uk/wp-content/uploads/2014/10/APPG_Manifesto.pdf (accessed on 15 April 2015).

Alvesson M. 2003. Beyond neopositivists, romantics, and localists: A reflexive approach to interviews in organizational research. Academy of Management Review 28(1):13-33.

Anderson P, De Bruijn A, Angus K, Gordon R, Hastings G. 2009. Impact of alcohol advertising and media exposure on adolescent alcohol use: a systematic review of longitudinal studies. Alcohol and Alcoholism 115(1): 1-15.

Antonetti P, Baines P, Walker L. 2015. From elicitation to consumption: assessing the longitudinal effectiveness of negative emotional appeals in social marketing. Journal of Marketing Management 31(9-10): 940-969.

Barrios A, Piacentini MG, Salciuviene L. 2012. Your life when you've got everything is different: Forced transformations and consumption practice. Research in Consumer Behavior 14: 129-141.

Bearden WO, Etzel MJ. 1982. Reference Group influence on product and brand purchase decisions. Journal of Consumer Research 9(2): 183-194.

Berger J, Rand L. 2008. Shifting signals to help health: Using identity signalling to reduce risky health behaviours. Journal of Consumer Research 35(3): 509-518.

Bold C. 2011. Using narrative in research. Sage Publication: London.

Borsari B, Carey KB. 2001. Peer Influences on College Drinking: A Review of the Research. Journal of Substance Abuse 13(4): 391-424.

Bot SM, Engels RC, Knibbe RA, Meeus, WH. 2005. Friend's drinking behaviour and adolescent alcohol consumption: The moderating role of friendship characteristics. Addictive Behaviors 30(5): 929-947.

Brown R. 2000. Social Identity Theory: Past achievements, current problems and future challenges. European Journal of Social Psychology 30(6): 745-778.

Braun V, Clarke V. 2006. Using thematic analysis in psychology. Qualitative research in psychology 3(2): 77-101.

Cherrier H, Gurrieri L. 2013. Anti-consumption choices performed in a drinking culture normative struggles and repairs. Journal of Macromarketing 33(3): 232-244. 
Choi WJ, Winterich KP. 2013. Can brands move in from the outside? How moral identity enhances out-group brand attitudes. Journal of Marketing 77(2): 96-111.

Cochrane R, Bal S. 1990. The drinking habits of Sikh, Hindu, Muslim and white men in the West Midlands: a community survey. British Journal of Addiction 85(6): 759-769.

Creswell JW. 2009. Research Design: Qualitative, Quantitative, and Mixed Method Approaches (3rd edition). Sage Publications: Los Angeles, CA.

Escalas JE, Bettman JR. 2005. Self-construal, reference groups, and brand meaning. Journal of Consumer Research 32(3): 378-389.

Fry ML. 2010. Countering consumption in a culture of intoxication. Journal of Marketing Management 26(13-14): 1279-1294.

Griffin C, Bengry-Howell A, Hackley C, Mistral W, Szmigin I. 2009. Every time I do it I absolutely annihilate myself': loss of self- consciousness and loss of memory in young people's drinking narratives. Sociology 43(3): 457-476.

Hackley C, Bengry-Howell A, Griffin C, Mistral W, Szmigin I, Tiwsakul RAHN. 2013. Young adults and 'binge' drinking: a Bakhtinian analysis. Journal of Marketing Management 29(7-8): 933-949.

Ham LS, Hope DA. 2003. College students and problematic drinking: a review of the literature. Clinical Psychology Review 23(5): 719-759.

Heath DB. 2000. Drinking Occasions: Comparative Perspectives on Alcohol and Culture. Routledge: London.

Heath T, O'Malley L, Heath M, Story V. 2014. Caring and conflicted mothers' ethical judgements about consumption. Journal of Business Ethics 136(2): 237-250.

Heim D, Hunter SC, Ross AJ, Bakshi N, Davies JB, Flatley KJ, Meer N. 2004. Alcohol consumption, perceptions of community responses and attitudes to service provision: Results from a survey of Indian, Chinese and Pakistani young people in greater Glasgow, Scotland, UK. Alcohol and Alcoholism 39(3): 220-226.

Herring R, Berridge V, Thom B. 2008. Binge drinking: an exploration of a confused concept. Journal of Epidemiology and Community Health 62(6): 476-479.

Hoek J, Jones SC. 2011. Regulation, public health and social marketing: a behaviour change trinity. Journal of Social Marketing 1(1):32-44.

Hogg MA, Abrams D. 2001. Social Identifications: A Social Psychology of Intergroup Relations and Group Processes. Routledge: Sussex. 
Hudson LA, Ozanne, JL. 1988. Alternative ways of seeking knowledge in consumer research. Journal of Consumer Research 14(4): 508-521.

McAlexander JH. 1991. Divorce, the disposition of the relationship, and everything. Journal of Advances in Consumer Research 18(1): 181-190.

McCracken G. 1986. Culture and Consumption: a Theoretical Account of the Structure and Movement of the Cultural Meaning of Consumer Good. Journal of Consumer Research 13(1): 71-84.

Measham F, Brain K. 2005. 'Binge' drinking, British alcohol policy and the new culture of intoxication. Crime, Media, Culture 1(3): 262-283.

Miles MB, Huberman AM. 1994. Qualitative data analysis: A sourcebook. Sage Publications: Beverly Hills

Mooney DK, Corcoran KJ. 1991. Personal and perceived peer alcohol expectancies: their influences on alcohol consumption. Psychology of Addictive Behaviors 5(2): 85-92

Moraes C, Michaelidou N, Meneses R. 2014. The use of Facebok to promote drinking among young consumers. Journal of Marketing Management 30(13-14): 1377-1401.

Pace S. 2008. Youtube: an opportunity for consumer narrative analysis? Qualitative Market Research: An International Journal 11(2): 213-226.

Park CW, Lessig VP. 1977. Students and housewives: differences in susceptibility to reference group influence. Journal of Consumer Research 4(2): 102-110.

Piacentini MG, Banister EN. 2006. Getting hammered? Students coping with alcohol. Journal of Consumer Behaviour 5(2): 145-156.

Piacentini MG, Banister EN. 2009. Managing anti-consumption in an excessive drinking culture. Journal of Business Research 62(2): 279-288.

Piacentini MG, Chatzidakis A, Banister EN. 2012. Making sense of drinking: the role of techniques of neutralisation and counter neutralisation in negotiating alcohol consumption. Sociology of Health \& Illness 34(6): 841-857.

Price LL, Arnould EJ, Curasi CF. 2000. Older consumers' disposition of special possessions. Journal of Consumer Research 27(2):179-201.

Public health white paper 2010 and 2011 available at https://www.gov.uk/government/publications/the-public-health-white-paper-2010 and 2011 (accessed on 15 April 2015). 
Reed MB, Lange JE, Ketchie JM, Clapp JD. 2007. The relationship between social identity, normative information, and college student drinking. Social Influence 2(4): 269-294.

Ricoeur, P. (2002). "Narrative time" in Narrative Dynamics: Essays on time, plot, closure, and frames, Richardson, B. (ed.). Ohio State University: Colombus; 35-47.

Riessman CK. 2008. Narrative Methods for the Human Sciences. Sage Publication: London.

Rinker DV, Neighbors C. 2014. Do different types of social identity moderate the association between perceived descriptive norms and drinking among college students? Addictive Behaviors 39(9): 1297-1303.

Ryan GW, Bernard HR. 2003. Techniques to identify themes. Field methods 15(1): 85-109.

Schwandt TA. 1994. Constructivist, interpretivist approaches to human inquiry. In Handbook of qualitative research, Denzin NK, Lincoln YS (ed.), Thousand Oaks, CA: Sage; 118-137

Schiffrin D. 1996. Narrative as self-portrait: Sociolinguistic constructions of identity. Language in Society 25(02): 167-203.

Shankar A, Elliott R, Goulding C. 2001. Understanding consumption: Contributions from a narrative perspective. Journal of Marketing Management 17(3-4): 429-453.

Sher KJ, Rutledge PC. 2007. Heavy drinking across the transition to college: predicting firstsemester heavy drinking from precollege variables. Addictive Behaviors 32(4): 819-835.

Stets JE, Burke PJ. 2000. Identity Theory and Social Identity Theory. Social Psychology Quarterly 63(3): 224-237.

Szmigin I, Griffin C, Mistral W, Bengry-Howell A, Weale L, Hackley C. 2008. Re-framing 'Binge Drinking' as calculated hedonism: empirical evidence from the UK. International Journal of Drug Policy 19(5): 359-367.

Szmigin I, Bengry-Howell A, Griffin C, Hackley C, Mistral W. 2011. Social Marketing, individual responsibility and the "culture of intoxication". European Journal of Marketing 45(5): 759-779.

Tajfel H, Turner JC. 1979. An Integrative Theory of Intergroup Conflict, in The Social Psychology of Inter- group Relations, William GA, Stephen WM. (ed.) Nelson Hall: Chicago; $33-47$.

Tajfel H, Turner, JC. 1986. The Social Identity Theory of Intergroup Behavior, in Psychology of intergroup relations, Worchel S, Austin W. (ed.). Nelson-Hall: Chicago; 7-24.

Terry DJ, Hogg MA, White KM. 1999. The Theory of Planned Behaviour: self-identity, social identity and group norms. British Journal of Social Psychology 38(3): 225-244. 
The Varsity. 2015. Binge drinking endemic in student culture. Available at http://www.varsity.co.uk/news/13 (Accessed on 20 October 2015).

The walk to school booklet. Available at https://www.livingstreets.org.uk/what-we-do/walk-toschool (Accessed on 20 February 2017).

Webb E, Ashton CH, Kelly P, Kamali F. 1998. An Update on British Medical Students' Lifestyles. Medical Education 32(3): 325-331.

Wechsler H, Kuo M. 2000. College students define binge drinking and estimate its prevalence: results of a national survey. Journal of American College Health 49(2): 57-64.

White K, Dahl DW. 2006. To Be or Not Be? The influence of dissociative reference groups on consumer preferences. Journal of Consumer Psychology 16(4): 404-414.

White K, Dahl DW. 2007. Are all out-groups created equal? Consumer identity and dissociative influence. Journal of Consumer Research 34(4): 525-536.

White K, Simpson B, Argo JJ. 2014. The motivating role of dissociative out-groups in encouraging positive consumer behaviours. Journal of Marketing Research 51(4): 433-447. 


\section{Appendix 1}

Table 1: Background of the respondents

\begin{tabular}{|c|c|c|c|c|}
\hline Pseudonym & Age and Gender & Family background & $\begin{array}{c}\text { Religious } \\
\text { background }\end{array}$ & Locality \\
\hline Deepika & 22 year old female & Parents are professional and coming from a rich family. Less strict upbringing. & Hindu & New Delhi \\
\hline Juhi & 22 year old female & Parents are wealthy business people. Strict and a conservative family. & Sikh & Maharashtra \\
\hline Maduri & 23 year old female & Parents are modern rich business people. Less strict upbringing. & Jain religion & Pune \\
\hline Shoba & 24 year old female & Parents are wealthy business people. Less strict upbringing. & Roman Catholic & Mumbai \\
\hline Sonakshi & 25 year old female & Parents are conservative business people. Strict and a conservative family. & Hindu & New Delhi \\
\hline Wadiya & 22 year old female & Conservative religious family. Parents are upper middle class professionals. & Hindu & New Delhi \\
\hline Arun & 25 year old male & Parents are professionals/business owners and strict upbringing. & Christian orthodox & Chennai \\
\hline Choudhry & 25 year old male & Parents are middle class professionals and strict upbringing. & Hindu Brahmin & Mumbai \\
\hline Jeshan & 23 year old male & Parents are middle class professionals. Strict upbringing. & Christian orthodox & Kerala \\
\hline Kanna & 26 year old male & Parents are professionals and strict upbringing. & Roman Catholic & Ranchi \\
\hline Kumar & 25 year old male & Parents are professionals and less strict upbringing. & Hindu Brahmin & Bangalore \\
\hline Ranjan & 22 year old male & Middle class family. Father is a professional. Strict upbringing. & Jain & Mumbai \\
\hline Rizwan & 25 year old male & Middle class strict family. & Islam & Pune \\
\hline Safhaan & 22 year old male & Parents are rich business people. Traditional and strict. & Hindu & Bihar \\
\hline Sasen & 22 year old male & Parents are from a rich political family. Less strict upbringing. & Hindu & Haryana \\
\hline Shahid & 23 year old male & Rich traditional Muslim family and strict upbringing. & Islam & Bangalore \\
\hline Shahruck & 22 year old male & Parents are medical professionals Less strict modern family. & Hindu & Pune \\
\hline Shashan & 24 year old male & Business people and less strict upbringing. & Jain & New Delhi \\
\hline
\end{tabular}

